\title{
Multistage configurations for hybrid thermosolar gas turbine power plants
}

\author{
C. Miguel ${ }^{1}$, R.P. Merchán ${ }^{1}$, M.J. Santos ${ }^{1}$, A. Calvo Hernández ${ }^{1}$, and A. Medina ${ }^{1}$ \\ ${ }^{1}$ Department of Applied Physics \\ University of Salamanca \\ Pza. de la Merced, s/n - 37008 Salamanca (Spain)
}

Phone/Fax number:+0034 923294436, e-mail: cesarmi@usal.es, rpmerchan@usal.es, smjesus@usal.es, anca@usal.es, amd385@usal.es

\begin{abstract}
.
This work presents a thermodynamic model for a hybrid multistage Brayton thermosolar plant, with the aim of evaluating the efficiency and the power generation in different plant configurations. Improvements with respect a hybrid single stage Brayton thermosolar plant are proposed. This type of plants have two main energy sources for its operation, one from solar radiation, and the other one from the fuel combustion in a combustion chamber, making the values of the fuel consumption and the greenhouse emissions lower than other types of electric power generation plants. Moreover, this technology allows a stable power output (independent of solar irradiation fluctuations) without thermal storage systems.
\end{abstract}

\section{Key words}

Hybrid thermosolar plant, multistage Brayton cycle, thermodynamic model with irreversibilities, global plant efficiency, greenhouse emissions.

\section{Interest of the work}

The necessity to find new ways to obtain clean energy is undoubted. Renewable resources substituting (at least partially) fossil fuels are imperative. For this reason, in the last years several studies had been focused in the development of prototypes and experimental plants in order to investigate the viability of thermosolar hybrid Brayton cycle plants.

Thermosolar technology is one of the main ways of solar energy exploitation. The objective of Brayton hybrid plants is to concentrate solar energy to heat a working fluid, usually air, before entering a combustion chamber. Then, the fluid performs a thermodynamic cycle generating electrical energy indirectly (a Brayton like cycle in our case). In this way fossil fuel and the associated emissions are reduced. Another advantage of these facilities is their low water consumption, which makes them suitable for electrical generation in arid regions [1].

$\mathrm{R}+\mathrm{D}$ studies done during the last years have shown the technical viability of these plants but at the same time the need to improve efficiency, in order to generate electricity at competitive prices.

\section{Objectives}

The main objective of this work is to develop a thermodynamic model, for a multistep thermosolar hybrid gas turbine plant with the purpose to analyze the influence of multistep compression and expansion processes on the global plant efficiency. The model was validated in recent works, for the case of a single stage cycle with the results of the prototype plant called SOLUGAS [2]. In this work we extend previous models [3-5] in order to incorporate multistage compression and expansion processes looking for improving the plant output records in which respect to increase overall efficiency and decrease fuel consumption and emissions. The model includes all the main losses existing in real plants.

\section{Thermodynamic model.}

This study is restricted to Central Receiver Systems (CRS) $[3,6]$. These plants have three main elements. The first one is the heliostat field formed by an array of mirrors that reflect and focus solar radiation to the receiver, which is the second element of the plant. It is located at the top of the tower and converts solar radiation into heat at high temperatures. Finally, the power conversion system transforms thermal energy into electrical energy. 


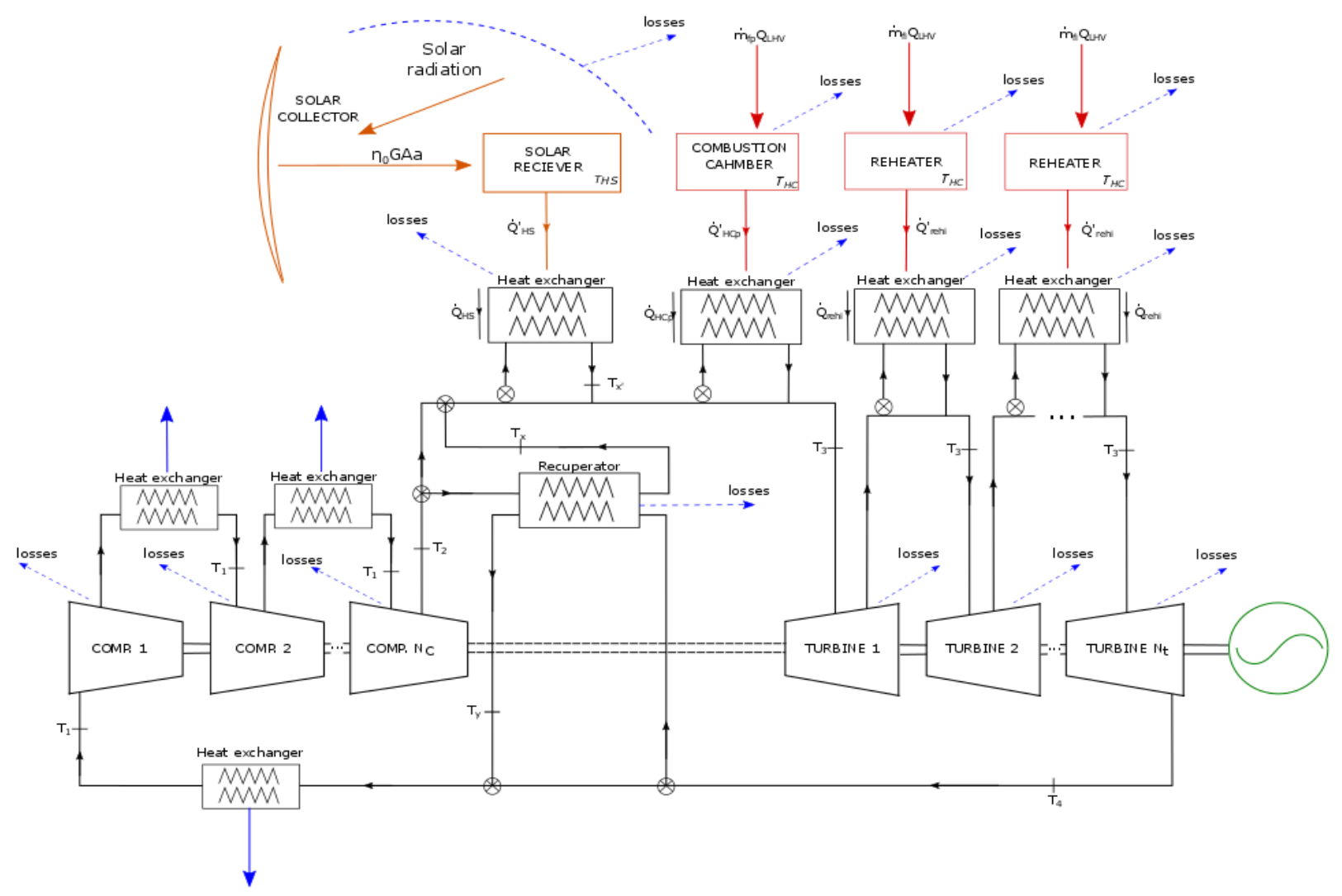

Figure 1. Scheme of the thermosolar hybrid Brayton plant considered.

The operation of the plant, in general terms, can be described in the following way. First, the working fluid (air in this case) starts the cycle with a temperature $\mathrm{T}_{1}$, which is approximately the ambient temperature. Then, its pressure is increased by an arbitrary number of $\mathrm{N}_{\mathrm{c}}$ compressors, reaching a temperature $\mathrm{T}_{2}$. In the next stage, the temperature is increased to the temperature $T_{3}$. This process is made in three subprocesses: first, the recuperator increases the temperature until $\mathrm{T}_{x}$; the next increase of temperature is made by the solar collector, which allows the fluid to reach a temperature $T_{x}$; , and finally, the combustion chamber increases the temperature to $T_{3}$, which is the turbine inlet temperature. Afterwards, the fluid is expanded by means of an arbitrary number of turbines, $\mathrm{N}_{\mathrm{t}}$, originating mechanical energy that is transformed to electric energy by an electric generator. Then, the air decreases its temperature until $\mathrm{T}_{4}$. Finally, the fluid recovers its initial temperature by two processes. In the first one, the recuperator transfers part of the heat to the ongoing fluid and decrease the temperature until $\mathrm{T}_{\mathrm{y}}$. Then, the fluid enters in a heat exchanger where temperature is decreased up to the initial temperature $T_{1}$, releasing heat to the ambient.

In the expansion through multiples turbines, $\mathrm{N}_{\mathrm{t}}-1$ reheaters are required, one between each pair of turbines, assuring that the temperature at the entrance of each turbine is $\mathrm{T}_{3}$. In the same way, in the compression $\mathrm{N}_{\mathrm{c}}-1$ intercoolers are included, one between each pair of compressors, ensuring that the temperature at the entrance of each compressor is $\mathrm{T}_{1}$ (see Fig.1).

For the solar subsystem a simple model for CRS systems, which takes into account heat losses in the solar collector due to radiation and conduction/convection terms, was assumed. The optical efficiency is an averaged effective factor.

The model allows a direct calculation of the plant operation records, particularly with variable number of turbines and compressors. Irreversibilities arising losses in the different elements of the plant have been taken into account.

\section{Results}

The SOLUGAS project in Spain was elected as prototypical installation to compare model predictions with. This is a $\mathrm{R}+\mathrm{D}$ project, developed by Abengoa company, placed in Sanlúcar la Mayor (Seville) [2] and it constitutes one of the most important ongoing projects about hybrid central receiver systems at a precommercial scale. The project intends to generate a stable power output around $5 \mathrm{MW}$. Our model, for the simple one stage case was recently validated with this installation [2]. Comparison of model predictions with respect to output parameters of the experimental plant are very satisfactory in the case of one turbine and one compressor. Explicit tables with the main plant parameters and the results of validation can be found in [3-5]. 
After the validation in stationary conditions, variable number of turbines and compressor were incorporated to our computational scheme. For the sake of brevity explicit equations are not shown here. Predictions of global plant thermal efficiency, efficiencies of the subsystems, solar share, power output, temperatures in the cycle, fuel combustion and emissions have been obtained as a function of the number of compression/expansion stages for the design point of the SOLUGAS plant.

\section{A. Efficiencies and solar share.}

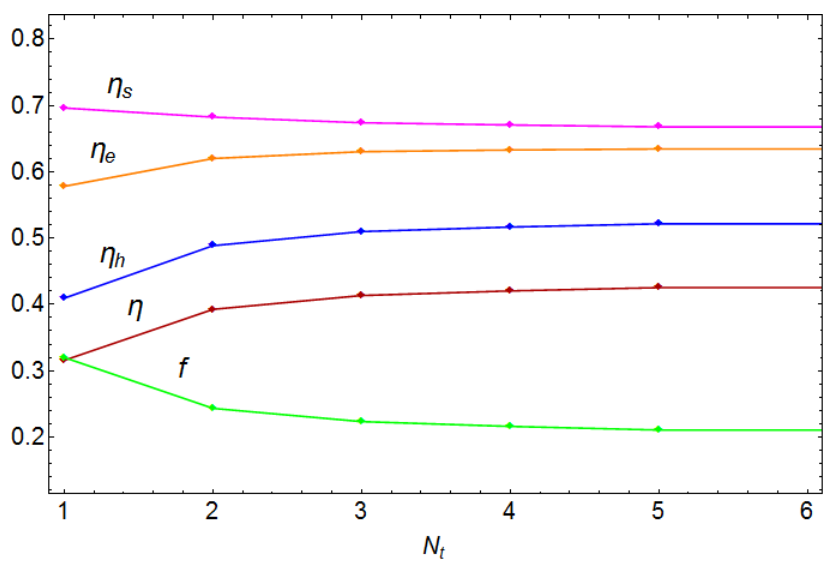

Figure 2. Evolution of plant efficiencies with the number of turbines: solar collector efficiency $\left(\eta_{s}\right)$, thermal efficiency of thermal Brayton engine $\left(\eta_{h}\right)$, fuel conversion rate $\left(\eta_{e}\right)$, overall thermal efficiency $(\eta)$ and solar share $(f)$.

The behaviour of the efficiencies is represented in Fig. 2 for the case in which $N_{t}=N_{c}$. The efficiency of heat engine $\left(\eta_{h}\right)$, global efficiency $(\eta)$ and the fuel conversion rate $\left(\eta_{e}\right)$ show an increasing trend as the number of turbines is increased. On the other hand, the solar share $(f)$ and the solar efficiency $\left(\eta_{s}\right)$ present a downward trend as the number of turbines is increased. It can be appreciated that when the number of turbines is bigger than 5 the efficiencies and solar share reach saturation values. It is noteworthy that the largest increase is found when passing from the single stage configuration to that with two compressors and two turbines.

\section{B. Power output.}

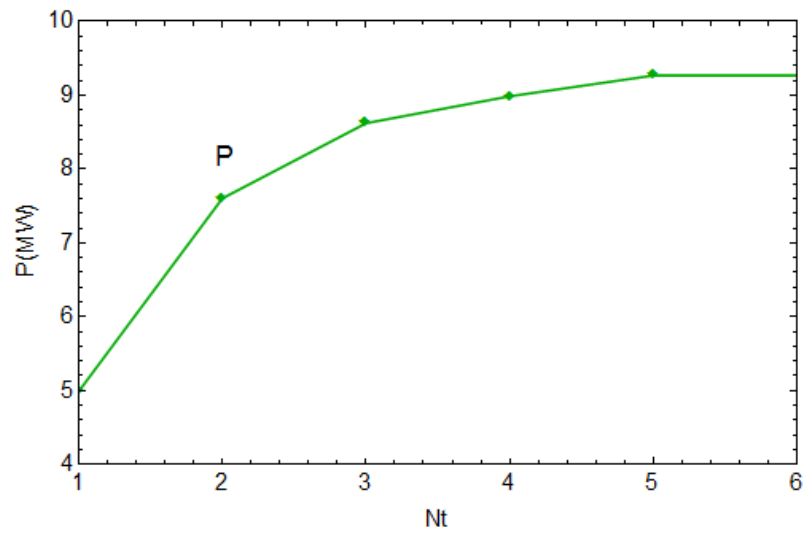

Figure 3. Evolution of the plant power output with the number of turbines.
The obtained power output is represented in Fig. 3. It also shows an increasing trend, where in the step from 1 to 2 turbines the relative rise is $47,9 \%$ increasing the output power up $7 \mathrm{MW}$. As it was shown in the last section, when the number of turbines is above 4 , the power output shows a saturation behaviour.

\section{Temperatures.}

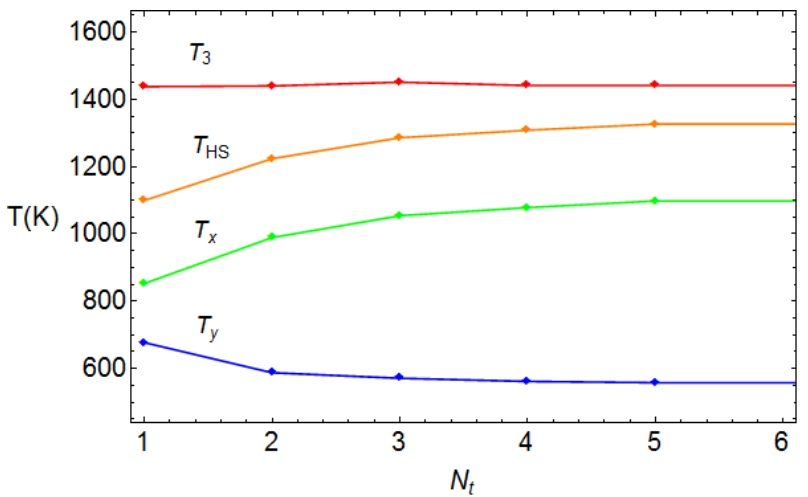

Figure 4. Evolution of plant temperatures with the number of turbines: turbine inlet temperature $\left(T_{3}\right)$, temperature of the solar collector $\left(T_{H S}\right)$, temperature of the working gas in the hot side after recuperation $\left(T_{x}\right)$ and temperature in the cold side after recuperation $\left(T_{y}\right)$.

The behaviour of the temperatures of the fluid in the cycle is represented in Fig. 4. The turbine inlet temperature $\left(T_{3}\right)$ is practically constant because it is a fixed design parameter. The temperature of the solar collector $\left(T_{H S}\right)$ and the temperature after the first heat input $\left(T_{x}\right)$ show an increasing trend with an asymptotic behaviour. The temperature at the exit of the recuperator $\left(T_{y}\right)$ tends to decrease as the number of turbines increase.

\section{Fuel consumption rate and emissions.}

In Fig. 5 the fuel consumption rate and the emissions of the greenhouse gases $\mathrm{CO}_{2}, \mathrm{CH}_{4}$ and $\mathrm{N}_{2} \mathrm{O}$, compared with the number of turbines are displayed. These results were obtained by relations between the fuel consumed and the amount of greenhouse gases that the fuel generates [7]. As the number of turbines increases, fuel consumption also does. This is a reasonable result provided that the number of rehaters increases with $N_{t}$ so fuel consumption and greenhouse emissions subsequently grow up.

\section{Conclusion}

In this work a thermodynamic non-stationary model for a thermosolar hybrid multistage plant, where the energy generation is based on the hybridization of a central receiver heliostat field and a Brayton gas multistage turbine, was developed.

This model allows to obtain analytical equations for magnitudes like the global efficiency, the power, the economic efficiency and other output records. A study in terms of the symmetrical number of turbines and compressors is performed. 

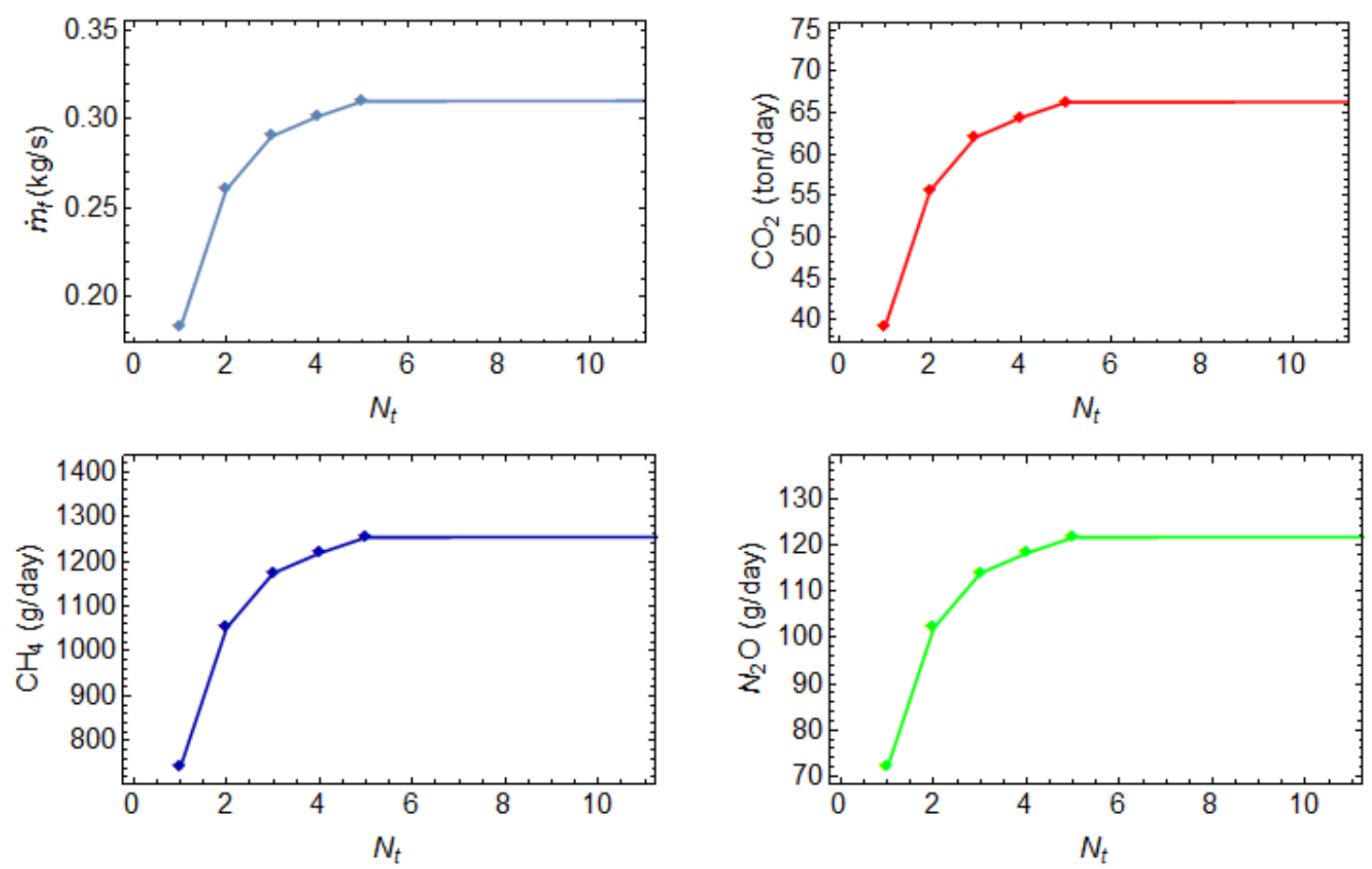

Figure 5. Evolution with number of turbines of the fuel consumption rate, $\left(m_{f}\right)$, supposed natural gas, and real units estimation of greenhouse emissions from the considered model.

Considering the same number of turbines and compressors, power raises up to a maximum value when increasing the number of turbines. At the same time solar share decreases. All variables, including fuel consumption and emissions, evolve with the number of stages up to a saturation value, which is around $N_{t}=5$. It is observed a significant increase of power output and overall efficiency when passing from a monostep plant layout to another one with two compressors and two turbines $N_{t}=2$. However, this increase is progressively reduced as the number of compression/expansion stages rises up.

Projects like this one could be useful for the pre-design of future plants of the same type. Nowadays, these plants are not as economically competitive as other, so it is necessary a $\mathrm{R}+\mathrm{D}$ work looking for configurations with greater efficiency in relation to fuel consumption.

\section{Acknowledgement}

Financial support from MINECO of Spain, Grant ENE2013-40644-R is acknowledged.

\section{References}

[1] O. Behar, A. Khellaf, K. Mohammedi. "A review of studies on central receiver solar termal plants". Renew. Sust. Energ. Rev. 23: 12-39 (2013).

[2] R. Korzynietz, J. A. Brioso, A. del Río, M. Quero, M. Gallas, R. Uhlig, M. Ebert, R. Buck, D. Teraji.

"Solugas - Comprehensive analysis of the solar hybrid Brayton plant”. Sol. Ener., 135, 578-589 (2016).

[3] M. J. Santos, R. P. Merchán, A. Medina, and A. Calvo Hernández. "Seasonal thermodynamic prediction of the performance of a hybrid solar gas-turbine power plant". Energ. Convers. Manage., 115, 89-102 (2016).

[4] S. Sánchez-Orgaz, A. Medina, A. Calvo Hernández. "Thermodynamic model and optimization of a multi-step irreversible Brayton cycle". Energ. Conv. Manage., 51, 213443 (2010);

[5] D. Olivenza-León, A. Medina, A. Calvo. "Thermodynamic modeling of a hybrid solar-turbine power plant". Energ. Conv. Manage. 93: 435-447 (2015).

[6] M. Romero, R. Buck, E. Pacheco. "An Update on Solar Central Receiver Systems, Projects, and Technologies". Transactions of the ASME, 124: 98 (2002).

[7] Emissions factors for greenhouse gas inventories: Table 1 stationary combustion emission factors. http://www.epa.gov/ghgreporting/documents/pdf/2013/docume nts/memo-2013-technical-revisions.pdf 